Provided by the author(s) and University of Galway in accordance with publisher policies. Please cite the published version when available.

\begin{tabular}{|c|l|}
\hline Title & Behaviour of tubular steel members under cyclic axial loading \\
\hline Author(s) & Goggins, Jamie; Broderick, Brian Michael; Lucas, AS \\
\hline $\begin{array}{c}\text { Publication } \\
\text { Date }\end{array}$ & 2006 \\
\hline $\begin{array}{c}\text { Publication } \\
\text { Information }\end{array}$ & $\begin{array}{l}\text { Goggins, J; Broderick, BM; Elghazouli, AY; Lucas, AS (2006) } \\
\text { Journal Of Constructional Steel Research, 62 (01-Feb):121- } \\
131 .\end{array}$ \\
\hline $\begin{array}{c}\text { Item record } \\
\text { http://hdl.handle.net/10379/3687 }\end{array}$ \\
\hline
\end{tabular}

Downloaded 2023-04-26T11:27:43Z

Some rights reserved. For more information, please see the item record link above.

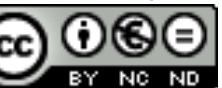




\title{
Behaviour of Tubular Steel Members under Cyclic Axial Loading
}

\author{
J.M. Goggins ${ }^{\mathrm{a}}$, B.M. Broderick ${ }^{\mathrm{a}^{*}}$, A.Y. Elghazouli ${ }^{\mathrm{b}}$ and A.S. Lucas ${ }^{\mathrm{a}}$ \\ ${ }^{a}$ Dept of Civil, Structural \& Environmental Engineering, Trinity College, Dublin, Ireland. \\ ${ }^{\mathrm{b}}$ Dept of Civil \& Environmental Engineering, Imperial College, London, UK.
}

\begin{abstract}
This paper examines the cyclic performance of axially-loaded tubular members used as bracing elements to provide lateral seismic resistance in steel framed structures. An experimental study into the response of members with square and rectangular hollow sections, made from cold-formed steel, is described. Three cross-sectional geometries were employed to represent a range of local and overall slenderness. Fifteen specimens, with normalised slendernesses between 0.4 and 3.2, were tested under cyclic axial displacements of increasing amplitude. In addition, twenty-one short specimens were tested under displacement-controlled monotonic tension loading, focusing primarily on the relationship between the tensile resistance of the material and that of the cross-section. Based on the results obtained in both sets of tests, and with due consideration of existing design provisions, the paper assesses the influence of section and member properties on the structural parameters that are most important for seismic design. These include the tensile capacity, initial and post-buckling compressive resistance, ductility capacity, energy dissipation, and mid-length lateral deformations of bracing members.
\end{abstract}

\section{Keywords}

Tubular members, cyclic axial loading, seismic resistance, buckling strength, hysteretic behaviour, ductility capacity.

\footnotetext{
* Dr. Brian Broderick, Department of Civil, Structural \& Environmental Engineering, Trinity College, Dublin 2, Ireland. Tel.: +353-1-6082348. Fax: +353-1-6773072. E-mail: bbrodrck@tcd.ie
} 


\section{Introduction}

The use of concentric braces in framed structures offers an attractive system for seismic resistance, primarily due their efficiency in providing lateral stiffness, hence limiting interstorey as well as overall lateral deformations. Nevertheless, the requirements of practical seismic design for ultimate conditions normally imply allowing buckling and yielding in the diagonal members, whilst preventing inelastic response in other components. Consequently, the cyclic axial response of the diagonal members, which are expected to undergo tension deformations beyond yield and compression deformations into the postbuckling range, represents the most crucial aspect of the seismic response of a braced frame system.

The experimental and analytical cyclic behaviour of bracing members has been the subject of investigation by several researchers. Earlier work (e.g. [1] and [2]) illustrated the distinctive hysteretic response of axially-loaded members. This is characterised by the gradual reduction in compressive resistance, as well as deterioration of stiffness in tension, with loading cycles of increasing deformation amplitude. These investigations also identified the improved stiffness and energy dissipation capabilities provided by relatively rigid end connections. In comparison with nominally pinned conditions, rigid connections cause plastic hinges to form at the member ends, in addition to that at mid-length, leading to improved inelastic performance.

Previous investigations on the cyclic behaviour of bracing members also identified a number of key response parameters, such as post-buckling resistance (e.g. [2] - [4[). These studies identified the strong influence of overall slenderness on the cyclic performance of bracing members, not only in terms of initial and post-buckling resistance, but also in terms of ductility capacity. It has been shown that members of lower slenderness may offer advantages in terms of relatively high compressive capacity and energy dissipation properties. Nonetheless, such members may possess comparatively low 
ductility due to the higher strain demands experienced in their plastic hinges. Similarly, while thin-walled hollow sections are very effective at resisting axial loads, they can be susceptible to local buckling at high compressive strains. During cyclic inelastic loading, the onset of local buckling reduces the ductility of the brace member and may lead to brittle failure.

Although seismic codes of practice, such as Eurocode 8 [5] and AISC [6] consider the main behavioural aspects of bracing members, they differ on the quantification of important design parameters and limiting criteria [7]. While these discrepancies may not be significant in conventional static design, which is largely based on conservative estimates of stiffness and capacity, appropriate implementation of the capacity design procedures adopted in seismic codes requires that the main response parameters be adequately quantified.

The experimental investigation described in this paper deals with the response of tubular steel members under cyclic axial loading conditions. The work forms part of a wider investigation undertaken in support of the development of Eurocode 8 [5]. The coldformed steel specimens were fabricated with hollow square and rectangular cross-sections. The selection of cross-section sizes and lengths employed was designed to ensure that the specimen member slendernesses covered most of the practical range. After describing the specimen details and material properties, a detailed assessment of tensile resistance is presented to relate basic material properties with the actual capacity obtained from monotonic tests. In the capacity design approach, this relationship influences the design of all elements in an earthquake resistant braced frame. The main observations and conclusions from the cyclic tests are then discussed. The key response parameters are identified and quantified, including an assessment of the initial and post-buckling resistance, ductility and energy dissipation, and mid-length deformation of members. 
Where appropriate, the findings are compared with the results of previous studies as well as existing code recommendations.

\section{Test Specimen and Arrangement}

All specimens were rectangular hollow sections (RHS) or square hollow sections (SHS) manufactured from cold-formed steel S235JRH, with a nominal yield strength of $235 \mathrm{~N} / \mathrm{mm}^{2}$ and an ultimate strength of between $360 \mathrm{~N} / \mathrm{mm}^{2}$ and $510 \mathrm{~N} / \mathrm{mm}^{2}$ [8].

Three cross-sectional geometries were considered, namely 40x40x2.5SHS,

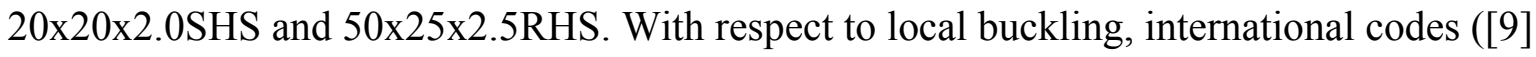
- [11]) classify the walls of these sections as Plastic or Class 1. Such sections should form plastic hinges capable of sustaining their moment capacity through large rotations. The measured $\mathrm{d} / \mathrm{t}$ ratios of these specimens are given in Table 1 , in which $\mathrm{d}$ is defined as in Eurocode 3 [11] as $\mathrm{h}-3 \mathrm{t}$, where $\mathrm{h}$ is the greater overall dimension of the section parallel to the principal axis and $t$ is the wall thickness. Two specimen lengths $\left(\mathrm{L}_{\mathrm{T}}\right)$ were examined intermediate $(1100 \mathrm{~mm})$ and long $(3300 \mathrm{~mm})$. As shown in Figure 1, fixed end restraints were employed for all test specimens and stiffener plates were placed to provide an adequate length of weld for the transfer of force between the brace and the supports and to encourage uniaxial flexural buckling. The specimens were manufactured in a rigid jig to ensure the base plates of the specimens were parallel, the holes aligned properly and all test specimens were of the same intended length within each group.

Fifteen cyclic tests were carried out- six on intermediate length specimens and nine on long specimens. These were in addition to 21 monotonic tensile tests on relatively short specimens (with aspect ratios of 3 to 1), which were carried out to compare section strength to the results of standard coupon tests, as discussed in the following section on tensile capacity. 
Two separate test rigs were employed, one for the monotonic tensile tests and cyclic tests on intermediate length $(1100 \mathrm{~mm})$ specimens and another to test the long $(3300 \mathrm{~mm})$ specimens [12], [13]. In all cyclic tests, the loading was applied according to the provisions of the ECCS [14], which stipulate the application of one cycle at each level of $0.25,0.5,0.75$ and $1.0 \delta_{y}$, followed by 3 cycles at each level of $2,4,6 \delta_{y}$, etc, where $\delta_{\mathrm{y}}$ is the estimated axial yield displacement. The results of the monotonic tensile tests on short specimens were used to evaluate these yield displacements and hence determine the amplitudes of the loading cycles.

The actual material characteristics of the steel specimens were determined from tensile coupons taken from the hollow sections, and tested in accordance with the European Standard BS EN 10002-1:2001 [15]. Three coupons were tested from each length of steel employed in cyclic tests and the mean yield strengths observed for each section size are given in Table 1. The material properties of the steel sections tested did not all meet the characteristics recommended in the American seismic provision [6]. More specifically, the average ratio of yield ( $0.2 \%$ proof stress) to tensile stress of the steel material was greater than 0.85 for almost all coupons tested. Also, the average percentage elongation after fracture $\left(\mathrm{A}_{50 \mathrm{~mm}}\right)$ of the coupons taken from the $20 \times 20 \times 2.0$ SHS specimens was lower than that for the other sized specimens, and was less than the minimum value of $20 \%$ recommended by AISC [6].

\section{Assessment of Tensile Capacity}

To compare the tensile capacities of hollow tubular members to the strength properties obtained from coupon tests, twenty-one short specimens were tested under monotonic tension. The short specimens were cut from the same lengths of steel used to fabricate the coupon and cyclic tests. Figure 2 illustrates the mode of failure displayed, which involves gross section necking, followed by fracture. 
A specific feature of cold-formed elements is that their yield strength can locally increase because of cold working. The yield and ultimate strengths measured in the coupon tests were used to estimate the yield strengths of the hollow cross-sections using prediction models given in European and American design standards that allow for the influence of cold working at the corners of the members. Eurocode 3 [11] defines an average yield strength $f_{y a}$, which may be determined from the results of full size tests or by the expression

$$
f_{y a}=f_{y b}+\frac{k n t^{2}}{A_{g}}\left(f_{u}-f_{y b}\right) \text { but } f_{y a} \leq \frac{f_{u}+f_{y b}}{2}
$$

where:

$t=$ the material thickness before cold-forming $(\mathrm{mm})$;

$A_{g}=$ the gross cross-sectional area $\left(\mathrm{mm}^{2}\right)$;

$k=$ a numerical coefficient that depends on the type of forming $(k=7$ for coldrolling and $k=5$ for other methods of forming);

$n=$ the number of $90^{\circ}$ bends in the cross-section with an internal radius $r \leq 5 t$

(fractions of $90^{\circ}$ bends are counted as fractions of $n$ );

$f_{y b}=$ the basic yield value of sheet;

$f_{u}=$ the basic ultimate tensile strength of sheet.

The American Standard [16] also provides specific expressions for an increased basic yield strength due to strain hardening:

$$
F_{y a}=C F_{y c}+(1-C) F_{y f}
$$

in which:

$$
F_{y c}=\frac{B_{c} F_{y}}{(R / t)^{m}}
$$




$$
\begin{aligned}
& B_{c}=3.69 \frac{F_{u}}{F_{y}}-0.819\left(\frac{F_{u}}{F_{y}}\right)^{2}-1.79 \\
& m=0.192 \frac{F_{u}}{F_{y}}-0.068
\end{aligned}
$$

where:

$F_{y a}=$ the full-section tensile yield strength;

$F_{y c}=$ the average tensile yield strength of the corners;

$F_{y f}=$ the average tensile yield strength of the flat;

$F_{y}=$ the virgin yield strength;

$F_{u}=$ the virgin ultimate strength;

$C=$ the ratio of corner area to total cross-sectional area;

$R=$ the inside-bend radius;

$t=$ the sheet thickness.

In Table 1 , the values of $f_{y a}$ and $F_{y a}$ calculated using equations (1) and (2) respectively, are compared with the experimental yield strengths measured in monotonic tensile tests on short specimens. Table 1 shows that cold forming lead to significant increases in yield strength for the larger section sizes (40x40x2.5SHS and 50x50x2.5RHS), but not for the smaller section size (i.e. 20x20x2.0SHS). Both the European and American Standards underestimated the observed increase in the overall yield strength of the larger sections, implying that the safe upper bound on the resistance of dissipative bracing members required for capacity design is not obtained. This underestimation is compounded by the observation that in this test series, the actual yield strengths of the sections were found to be, on average, 1.49 times their nominal yield strengths. This overstrength is significantly higher than the value of 1.3 recommended in the American seismic provision [6] and exceeds the capacity design factor of 1.35 specified in Eurocode 8 [11]. 
Both codes predicted increased yield strengths for the 20x20x2.0SHS specimens. However, no such increase was observed because, due to the narrow member width, parts of the coupon samples are likely to have experienced cold forming during the manufacture of the hollow sections. Moreover, welding of the stiffeners would have produced a softening effect due to the heating of these relatively small sections. Indeed, whilst all the $40 \times 40 \times 2.5$ SHS and $50 \times 25 \times 2.5$ RHS specimens fractured at mid-height as expected, the $20 \times 20 \times 2$ SHS specimens fractured close to their welds, where heat effects were greatest.

\section{Hysteretic Response}

Two series of tests were completed in which brace specimens were subjected to cyclic axial displacements. Test series 1 and 2 refer to specimens with intermediate (1100mm) and long $(3300 \mathrm{~mm})$ lengths, respectively. In test series 1 , the 20x20x2.0SHS specimens experienced biaxial buckling, while the stockier specimens experienced uniaxial buckling, as shown in Figure 3(a). In test series 2, all the square hollow sections experienced biaxial buckling, and only the 50x25x2.5RHS specimens buckled unixially.

In test series 1 , all specimens comprising sections with relatively large width-tothickness ratios (i.e. $40 \times 40 \times 2.5$ SHS and 50x25x2.5RHS specimens) experienced local buckling (as shown in Figure 4a) and necking at some stage in their tests. Local buckling and necking occurred both at mid-height of the specimens and close to the end stiffeners. Local buckling caused progressive strain localisation that was accentuated with each compressive cycle. When the steel was stretched in tension, small cracks formed at these locations, and repeated cycling eventually caused failure, as illustrated in Figures 3(b) and (c). Fracture occurred at mid-height in all specimens except CyIS4, which fractured close to an end stiffener. All 20x20x2.0SHS specimens in test series 2 also fractured at this location, where the welding process clearly had an influence on available ductility. None of the 20x20x2.0SHS specimens experienced local buckling. 
Local inward buckling occurred at mid-height of the long 40x40x2.5SHS and $50 \times 25 \times 2.5$ RHS specimens of test series 2 . However, no sign of fracture was evident up to displacements exceeding $40 \mathrm{~mm}$ in both directions, where the stroke of the actuator was reached.

The test results from the cyclic tests are summarised in Table 2, while typical hysteresis curves obtained from both test series are presented in Figures 4 and 5. Different aspects of these results are discussed in subsequent sections.

\section{Initial and Post-Buckling Compressive Strength}

The average initial buckling loads $\left(\mathrm{F}_{\mathrm{exp}}\right)$ observed for each combination of section size and length are presented in Table 3. These are compared with unfactored design strengths calculated with British ( $\left.\mathrm{F}_{\mathrm{BS}}\right)$ [10], American ( $\left.\mathrm{F}_{\mathrm{AISC}}\right)$ [9] and European $\left(\mathrm{F}_{\mathrm{EC} 3}\right)$ [11], structural steelwork design specifications. Values of $\mathrm{F}_{\mathrm{BS}}, \mathrm{F}_{\mathrm{AISC}}$ and $\mathrm{F}_{\mathrm{EC}-\mathrm{b}}$ were calculated using material properties obtained from the tensile coupon tests described previously. Additionally, for the $1100 \mathrm{~mm}$ long specimens, values of $\mathrm{F}_{\mathrm{EC}-\mathrm{c}}$ were calculated using the yield strengths obtained in full section tensile tests, in combination with European buckling curve 'c' (values of $\mathrm{F}_{\mathrm{EC}-\mathrm{b}}$ are based on buckling curve ' $\mathrm{b}$ '). Both approaches are allowed for cold-formed members [11]. Good agreement is observed between the design values based on material strength, and these in general underestimate the actual buckling resistance of the specimens, except that all codes overestimate the compressive resistance of the long $50 \times 25 \times 2.5$ RHS specimens. For the $1100 \mathrm{~mm}$ long specimens, values of $\mathrm{F}_{\mathrm{EC}-\mathrm{c}}$ show the best agreement with the experimental results.

In Figure 6, the buckling resistances, $\mathrm{F}_{\mathrm{cr}}$, from Table 3 have been normalized by the yield strength of the section and plotted against normalised slenderness. This facilitates direct comparison of the experimental results with the calculation methods employed by the different design standards. The normalised slenderness is represented by $(\bar{\lambda})$ of 
Eurocode 3 [11], which is defined for non-slender cross-sections as $\left(\mathrm{P}_{\mathrm{p}} / \mathrm{P}_{\mathrm{cr}}\right)^{0.5}$, in which $\mathrm{P}_{\mathrm{pl}}$ and $\mathrm{P}_{\mathrm{cr}}$ are the plastic section capacity and theoretical elastic (Euler) buckling load respectively. The limited ranges of brace slenderness allowed by earthquake-resistant design procedures are also shown. In general, the North American standard [9] seems to provide the best agreement, with Eurocode 3 [11] being more conservative. Overall, however, the results show that these design calculation models, which have been developed from quasi-static test results, remain applicable when the imposition of the buckling load is preceded by a number of small amplitude load cycles, as is typically experienced during earthquake loading.

After initial buckling, specimen compressive resistance reduced at larger axial compression deformations. Lower post-buckling resistance was also observed during the second and third cycle at a given displacement amplitude, as observable in Figures 4 and 5. Figure 7 presents a set of normalised compression envelope curves extracted from the cyclic results of specimens with different slendernesses. As expected, the compression resistance is larger for stockier specimens, but these specimens experience the greatest reductions in compressive resistance in the post-buckling range. This behaviour has been noted in earlier studies ([2]-[4]). In Figure 8, predictions of post-buckling resistance by Jain [2] are compared to the measured compression envelope curves. Good agreement is observed, except for the stockiest braces at low ductility demands. Similar predictions by Tremblay [4] tend to underestimate the post-buckling resistance, as displayed in Figure 12. However, it should be noted that Tremblay [4] employed a lower bound for the postbuckling resistance, whereas in Figure 14, upper bound experimental values are used (i.e. an envelope). Predictions by Remennikov \& Walpole [3] of the buckling resistance at a ductility (i.e. $\delta / \delta_{\mathrm{y}}$ ) of 5 were found to overestimate considerably the observed resistance at that point in the post buckling response of the specimens. 


\section{Displacement ductility capacity and energy dissipation}

The displacement ductility capacity $\left(\mu_{\Delta}=\delta / \delta_{\mathrm{y}}\right)$ of the intermediate length specimens (test series 1) varied from 7.5 to 29.7 (Table 2). Three properties of the specimens were observed to influence these values: yield strength, member slenderness and section widthto-thickness $(\mathrm{d} / \mathrm{t})$ ratio. A strong inverse relationship between yield strength and ductility capacity was observed, with the results of the monotonic tensile tests on short specimens suggesting the following relationship [12]:

$$
\mu_{\Delta}=22.4-14\left(f_{y}-f_{y, n o m}\right) / f_{y, n o m}
$$

Equation (6) was derived from linear regression of the results of 16 tests on 40x40x2.5 SHS and 50x50x2.5 RHS specimens, with a correlation coefficient $\left(\mathrm{R}^{2}\right)$ of 0.77 .

The values in Table 2 show that ductility capacity was directly proportional to member slenderness; a trend which had previously been noted by other researchers (for example, [2] and [4]). The variation of ductility capacity with section width-to-thickness (d/t) ratio does not show a clear trend, probably because of the small range of values assessed, and the confounding influence of specimen strength. Also, the ductility capacities of the $50 \times 25 \times 2.5$ RHS specimens were higher than those of the $40 \times 40 \times 2.5$ SHS specimens because the stiffer webs of the rectangular section improved the local buckling resistance of the flanges. After allowing for the influence of the yield strength of the individual specimens according to equation (6), the following linear relationships between ductility and member slenderness (equation 7) and section width to thickness ratio (equation 8) were obtained from test series 1 [12]:

$$
\begin{array}{ll}
\mu_{\Delta}=26.2 \bar{\lambda}-0.7 & \left(\mathrm{R}^{2}=0.78\right) \\
\mu_{\Delta}=29.1-1.07(\mathrm{~d} / \mathrm{t}) & \left(\mathrm{R}^{2}=0.61\right)
\end{array}
$$


In test series 2 , the displacement ductility of the $3300 \mathrm{~mm}$ long $20 \times 20 \times 2.0 \mathrm{SHS}$ specimens was limited by early fracture close to the ends of the specimen. The other, less slender, $3300 \mathrm{~mm}$ specimens were not tested to failure, but all survived displacement ductility demands of between 5.6 and 9.5, without displaying any indications of imminent failure. The brace ductility demand in symmetrical tension-compression bracing systems, such as concentrically braced frames, typically varies between 2 and 3, although values up to 4-6 have been observed [4]. Thus, the responses of all of the specimens tested, (expect for the long 20x20x2.0SHS specimens), suggest that cold formed tubular steel bracing members possess sufficient ductility capacity to be employed as dissipative elements in earthquake resistant design. Modification of the connection detail of the $20 \times 20 \times 2.0 \mathrm{SHS}$ specimens to prevent early fracture would lead to greater ductility capacities for these members.

The shapes of the force-displacement hysteresis curves shown in Figures 4 and 5 are governed by the tensile yield and ultimate strengths of the specimens, their initial buckling strengths and post-buckling compressive resistances, and their initial and subsequent loading/unloading stiffnesses. All of these parameters influence the area contained within the hysteresis loops, which reflects the energy dissipation capabilities of the individual specimens.

The average energy dissipated by specimens of different sections size and length is presented in Table 3, in terms of two indices $\mathrm{W}_{\text {tot }}$ and $\mathrm{W}_{\mu=4}$. Values of $\mathrm{W}_{\text {tot }}$ refer to the total energy dissipated during the tests, normalised by the elastic strain energy of the strut, which is a function of the strut section area and yield strength. Values of $\mathrm{W}_{\mu=4}$ are the energy dissipated in the first cycle at a ductility of 4, normalised in the same way [17]. The $\mathrm{W}_{\text {tot }}$ values show a large variation, reflecting, in part, the shapes of the different hysteresis curves, but also the different ductility capacities of the specimens, (or the maximum 
ductility demands imposed). The values of $\mathrm{W}_{\mu=4}$ shown, being based on the energy dissipated in a single cycle, represent a more useful basis on which to compare the behaviour of the different members. A clear dependence on brace slenderness is observed, with the least slender specimens dissipating up to five times more energy, in that single cycle of loading, than the most slender.

\section{Lateral brace deformations}

In the post-buckling range of response, the magnitude of the lateral deformation experienced by a strut increases with imposed axial displacement. Hence, for braces in steel frames undergoing seismic response, greater lateral deformations should be expected at higher displacement ductility demands. Reliable predictions of these lateral deformations are important for serviceability and life safety, as excessive values could cause damage to non-structural elements such as cladding and glazing.

Figure 10 shows how the measured lateral deformations displayed by the specimens in test series 2 increased with imposed axial displacement. Except in the elastic range, each value shown is the average of the three cycles imposed at a given amplitude. The behaviour of the specimens is highly consistent, both for a given specimen size, and between sizes. There is a slight tendency for lower lateral deformations to be observed with higher member slenderness; and the observed axial-lateral displacement relationship is not quite linear, with the lateral deformations increasing at a slightly lower rate at higher axial displacements.

By considering a plastic hinge model of a buckled fixed-ended strut, Tremblay [4] developed equation (9) to predict the lateral deflection of a bracing member as a function of axial displacement:

$$
\Delta=0.7\left[\delta_{\mathrm{c}} \mathrm{L}_{\mathrm{H}}\right]^{0.5}
$$


where $\Delta$ is the lateral deflection at mid-height, $\delta_{\mathrm{c}}$ is the axial compression displacement and $\mathrm{L}_{\mathrm{H}}$ is the length of the member between the plastic hinges at either end. For a fixed-ended strut, it may be assumed that $\mathrm{L}_{\mathrm{H}}=\mathrm{L}-2 \mathrm{~d}$, where $\mathrm{d}$ is the depth of the member in the plane of buckling. Values given by equation (9) are plotted alongside the observed responses of the specimens in Figure 10. Good or reasonable agreement is generally observed, except at large axial displacements where equation (8) is seen to underpredict the measured values.

\section{Conclusions}

The response of cold-formed hollow steel bracing members to cyclic axial loading has been investigated in a series of experiments. The test specimens were selected with three cross-section configurations in order to assess the response of members with a range of local and overall slenderness. Their hysteretic behaviour was examined in terms of initial and post-buckling compression capacity, as well as ductility capacity and energy dissipation capability. Particular attention was also given to the mid-length lateral deformation of the buckled test members. In addition to these cyclic tests, monotonic tensile tests were conducted on short specimens, which provided important information on the yield and ultimate tensile strengths of the members investigated, and on the influence of cold-forming. Appropriate assessment of each of these parameters is required for the capacity design procedures adopted in most codes of practice for earthquake-resistant design. The experimental results presented are also valuable for validating and calibrating analytical procedures for the inelastic seismic response of braced steel frames.

The monotonic tensile test results indicated that the yield strength of cold-formed hollow sections can be up to $30 \%$ greater than that indicated by coupon tests. However, methods presented in structural steelwork design codes tended to underestimate this 
increase. This implies that when these members are employed as dissipative braces in an earthquake-resistant design that follows the capacity design approach, the required safe upper bound on resistance will not be obtained. Although seismic design codes make provision for such effects through the use of element overstrength factors, the values employed by different codes were often exceeded by the ratio of ultimate to nominal strength displayed by many of the test specimens.

No increase in yield strength was observed in the smallest $(20 \times 20 \times 2.0 \mathrm{SHS})$ specimens tested, and these specimens generally failed prematurely at or close to the welded connections at either end. Hence, although the connection detail employed proved adequate for most section sizes, for others, additional care should be taken to ensure an adequate strength weld around the top of the stiffener plate, while still limiting the heating of small sections. Otherwise, the additional ductility offered by more slender elements under cyclic loading conditions will be compromised.

Under cyclic loading conditions, design values based on measured material strengths tended to underpredict the actual buckling resistance of almost all specimens, which if replicated in practice could lead to an underestimate of design forces, such as storey shear. An upper bound on initial buckling strength could be achieved by employing curve ' $b$ ' in Eurocode 3 with section, rather than material, strength.

At low ductility demands, the post-buckling compression resistance of a brace can influence the maximum seismic forces acting on the braced frame, while at high ductility levels, it affects the axial compression forces in column members. In the cyclic tests, once first buckling of the specimens had occurred, their compressive resistance decreased upon applying larger compression deformations, or during the second or third cycle at a given displacement amplitude. Compression resistance was larger for stockier specimens, but these specimens experienced greater reductions in compressive strength in the postbuckling range. The resistance displayed by specimens of varying slenderness at different 
ductility demands compared well with predictions by Jain et al [2]. The lateral deformation of the specimens was also observed to increase with imposed axial displacement, and reasonable agreement was achieved with predictions based on a plastic hinge model of the buckled strut [4].

Three factors were observed to influence the ductility capacity of the cyclically loaded specimens: yield strength, member slenderness and (to a lesser extent) section width-to-thickness (b/t) ratio. Regression relationships based on the response of the tensile and cyclic test specimens were proposed for all three. The highest ductility capacity was displayed by specimens with low yield strength, high member slenderness and small $\mathrm{b} / \mathrm{t}$ ratio. Despite the relatively low material fracture strain evidenced in some coupon tests, the observed displacement ductility capacities of the intermediate length specimens varied from above 5 to nearly 30. Ductility demands between 5 and 10 were survived by the longer specimens, so long as the response was not affected by poor connection performance. These values exceed the brace ductility demand likely to be imposed on symmetrical tension-compression bracing systems.

The total energy dissipated by the individual specimens mainly depended on their tensile strengths and ductility capacities. To facilitate better comparison, an energy index based on normalisation by the brace elastic strain energy was examined for one cycle of response at a ductility demand of 4 . This showed clearly that brace energy dissipation capability is inversely proportional to overall slenderness. Of course, this observation only remains relevant for deformations within the ductility capacity of the brace, which is directly proportional to brace slenderness.

\section{Acknowledgements}

The first author wishes to acknowledge the financial support of the Trinity Trust and Enterprise Ireland through the Ussher Fellowship and Student sponsorship no. 
BR/2000/056, respectively. The work described in this paper was carried out with the help of the technical staff of the structures laboratory at Trinity College Dublin.

\section{References}

[1] Popov, E.P., Zayas, V.A. \& Mahin, S.A. Cyclic inelastic buckling of thin tubular columns. Journal of the Structural Division 105(ST11): 2261-2277, 1979.

[2] Jain, A.K., Goel, S.C. \& Hanson, R.D. Hysteretic cycles of axially loaded steel members. Journal of the Structural Division 106(ST8): 1777-1795, 1980.

[3] Remennikov, A.M. \& Walpole, W.R. A note on compression strength reduction factor for a buckled strut in seismic-resisting braced system. Engineering Structures 20(8): 779-782, 1998.

[4] Tremblay, R. Inelastic seismic response of steel bracing members. J. of Constructional Steel Research 58: 665-701, 2002.

[5] CEN, prEN 1998-1. Eurocode 8: Design provisions for earthquake resistance of structures - Part 1-1: General rules, seismic actions and general requirements for structures, Draft No. 4, December 2001.

[6] AISC. Seismic Provisions for Structural Steel Buildings, American Institute of Steel Construction, Inc., Chicago, IL, May 2002.

[7] Elghazouli, A.Y. Seismic design procedures for concentrically based frames. Proc Inst Civil Engnrs Struct and Build, 2003; 156: 381-394, 2003.

[8] British Standards Institute, BS EN 10219-1:1997. Cold formed structural hollow sections of non-alloy and fine grain structural steels. Technical delivery requirements. BSI, London, 1997.

[9] AISC. Load and Resistance Factor Design Specification for Steel Hollow Structural Sections. AISC., Chicago, IL, 2000.

[10] British Standards Institute, BS 5950-1. Structural use of steelwork in building code of practice for design. Rolled and welded section. BSI, London, 2000. 
[11] CEN, ENV 1993-1-1. Eurocode 3: Design of steel structures - Part 1-1: General rules and rules for buildings. Part 1.3: General rules - Supplementary rules for cold formed thin gauge members and sheeting., 1996.

[12] Goggins, J. Earthquake resistant hollow and filled steel braces. PhD Thesis. Trinity College, University of Dublin, 2004.

[13] Lucas, A.S. Testing and Analysis of Steel Bracing Members for Earthquake Resistance, MSc Thesis, Trinity College, University of Dublin, 2003.

[14] ECCS. Recommended Testing Procedure for Assessing the Behaviour of Structural Steel Elements under Cyclic Loads, 1st Edition, Brussels, 1986.

[15] British Standards Institute, BS EN 10002-1:2001. Metallic materials - Tensile testing - Part 1: Method of test at ambient temperature. BSI, London, 2001.

[16] AISI. Cold-formed Steel Design Manual. American Iron and Steel Institute, 1996.

[17] Usami, T. \& Ge, H. B. Cyclic behaviour of thin-walled steel structures, numerical analyses. Thin-Walled Structures, 1998; 32(1/3), 41-80, 1998. 

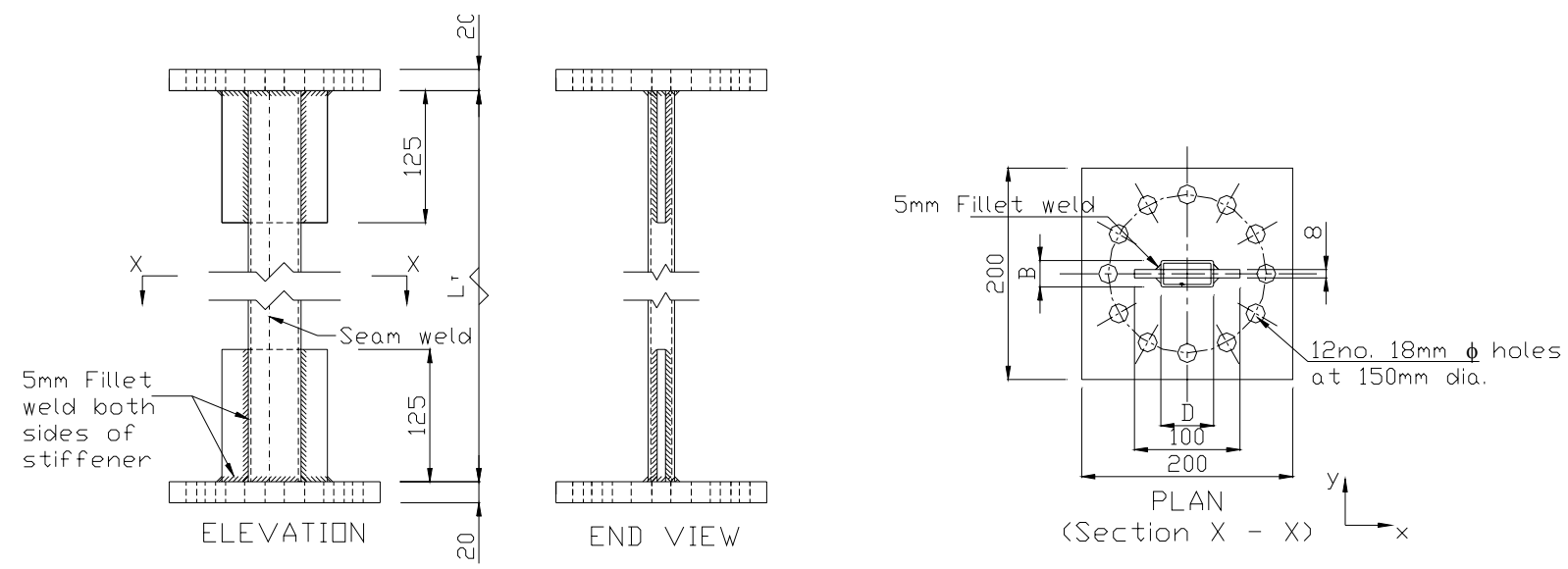

Figure 1. Test specimen. 

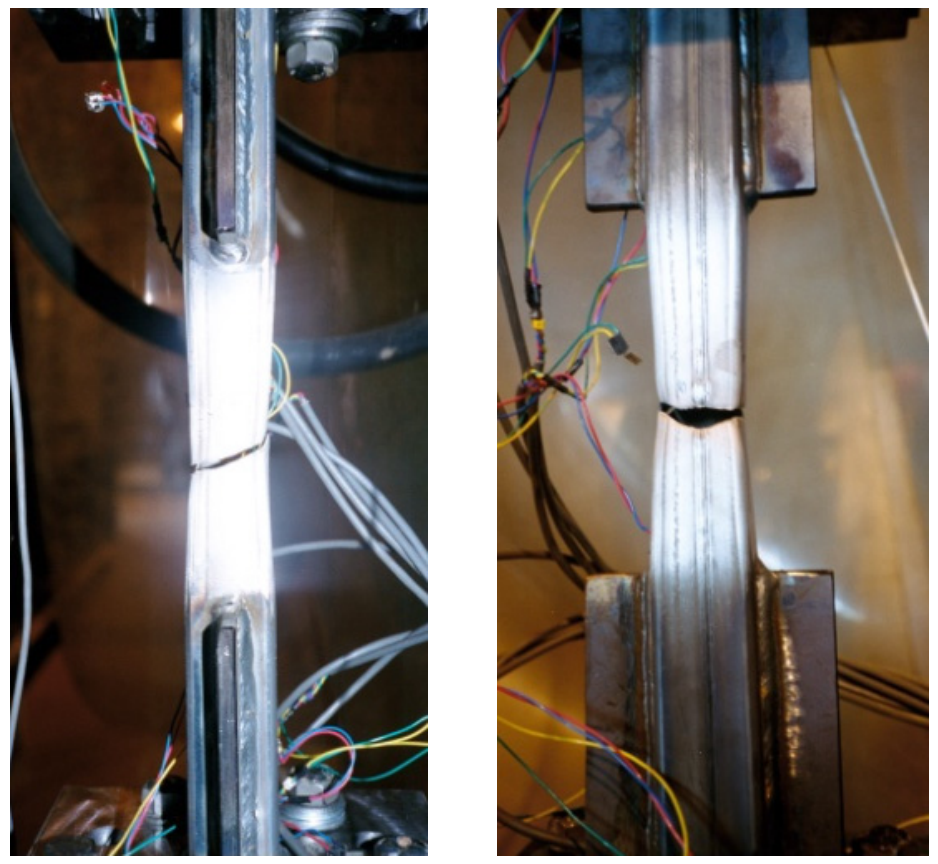

Figure 2: Typical failure of a short specimen in a monotonic tensile test

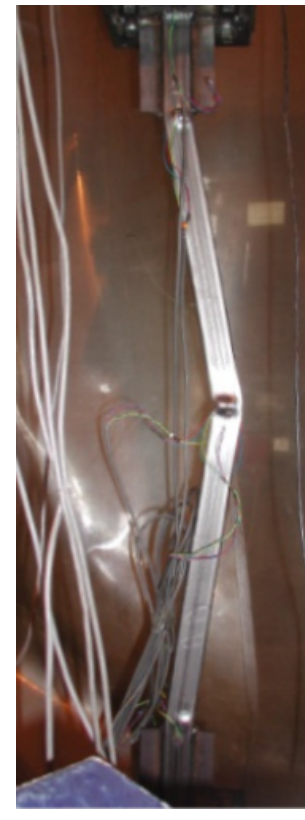

(a)

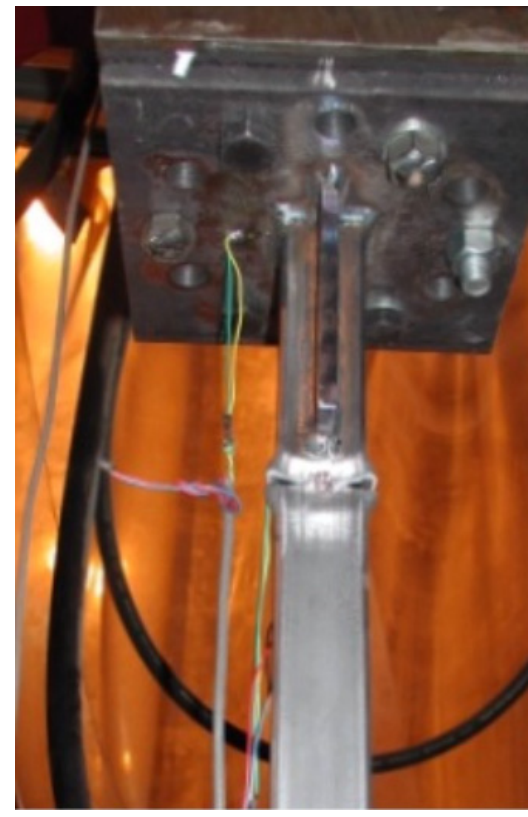

(b)

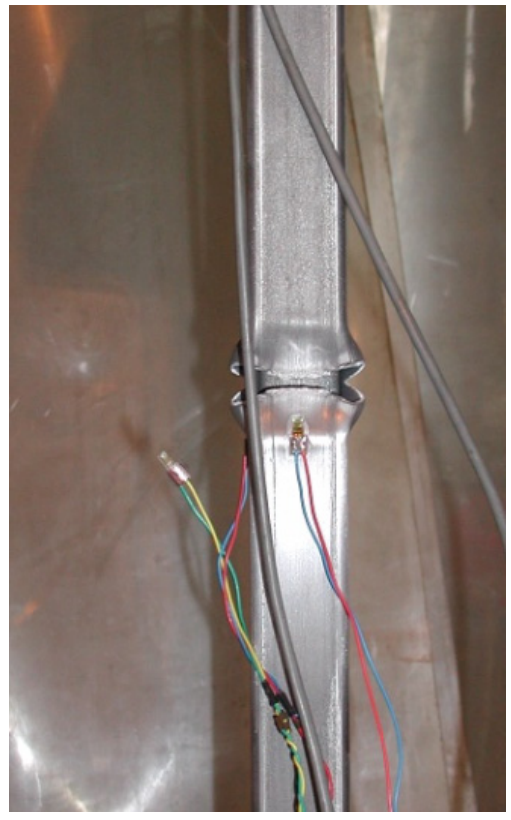

(c)

Figure 3. Failure of Specimen CyLS5. (a) Lateral and local buckling, (b) fracture across local buckle near top stiffener, (c) fracture across local buckle at mid-height. 

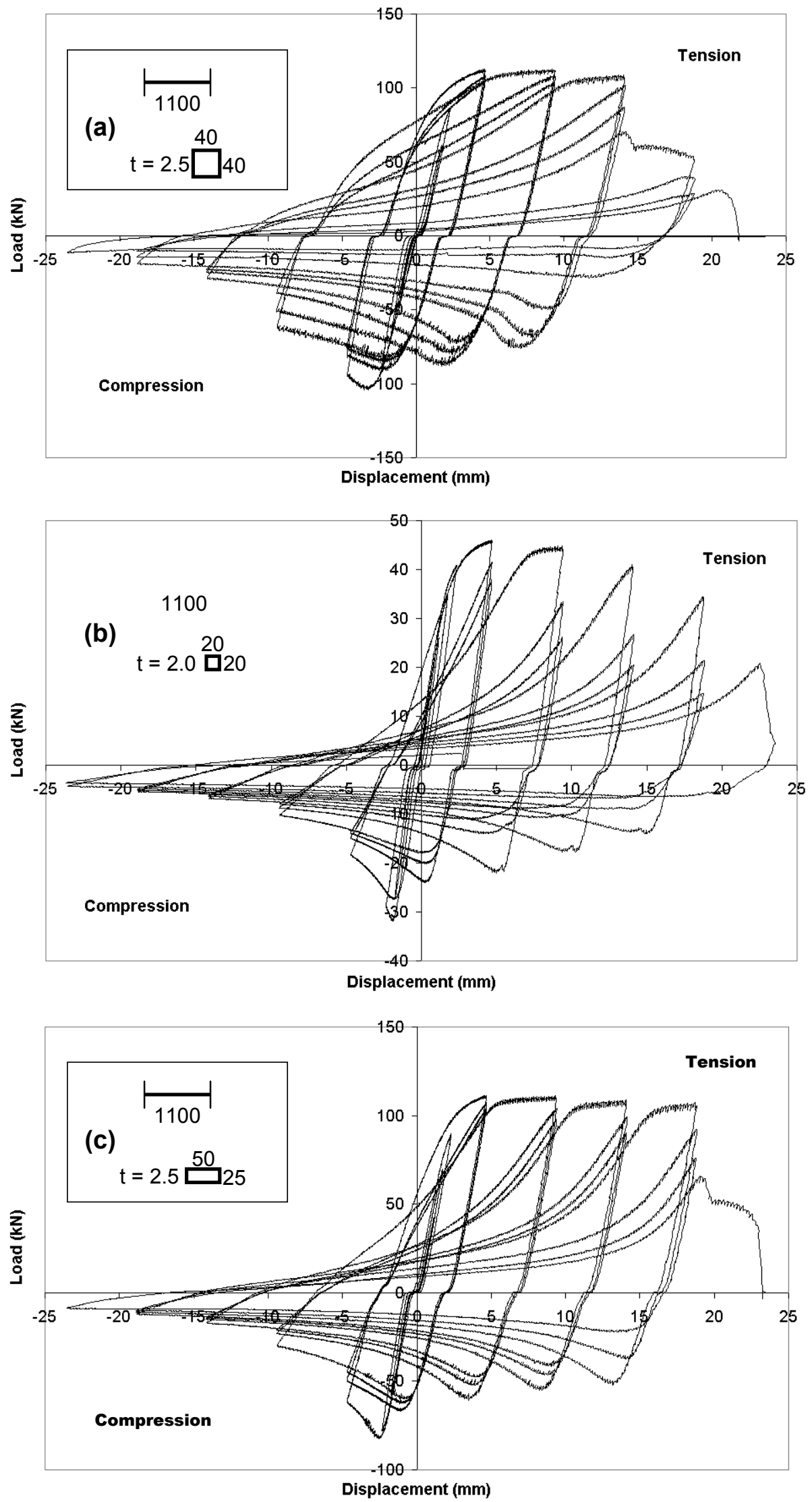

Figure 4. Load-displacement response of intermediate length specimens (a) CyIS1, (b) CyIS4, (c) CyIS5. Dimensions shown in millimetres. 

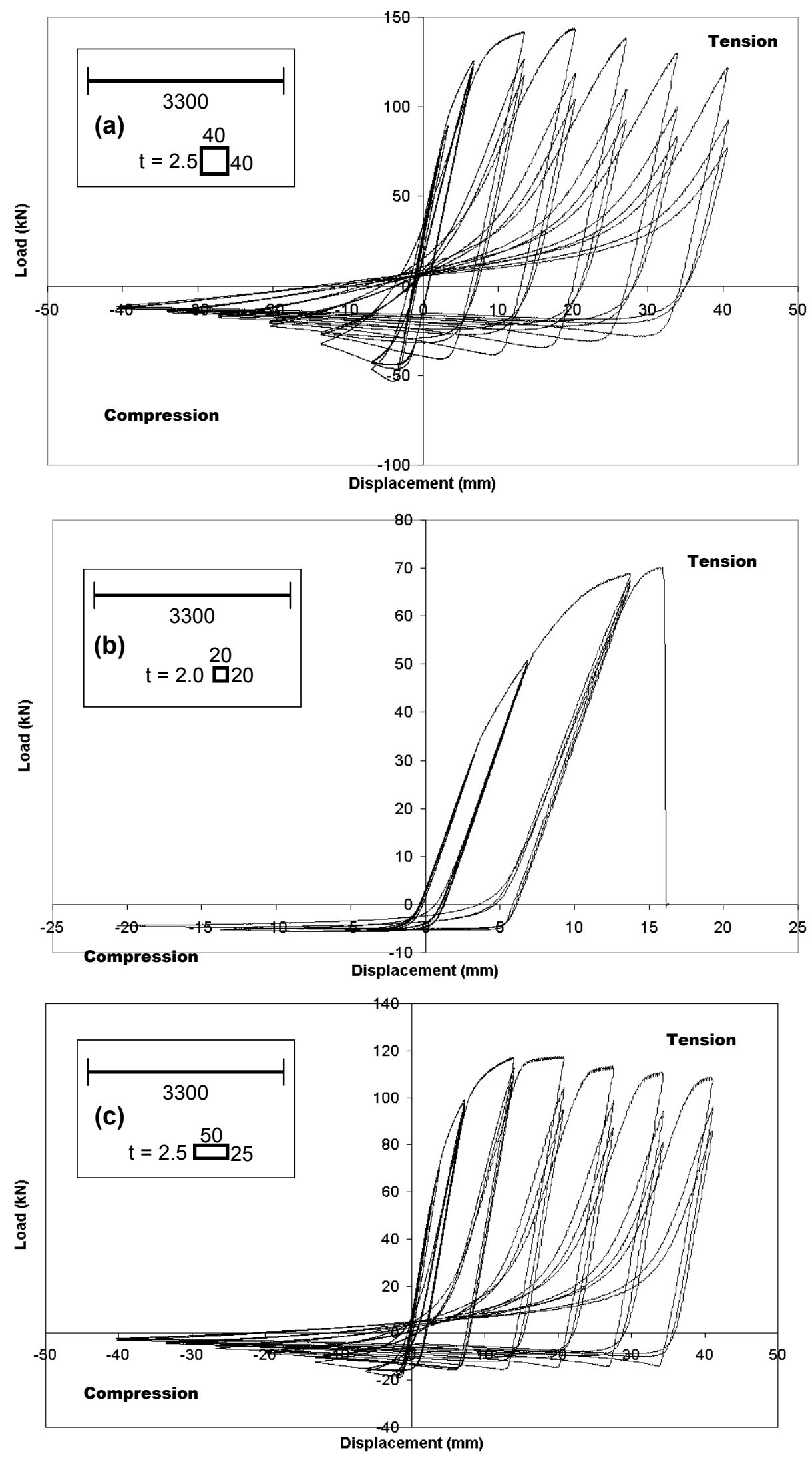

Figure 5. Load-displacement response of long specimens (a) CyLS1, (b) CyLS4, (c) CyLS7 Dimensions shown in millimetres. 


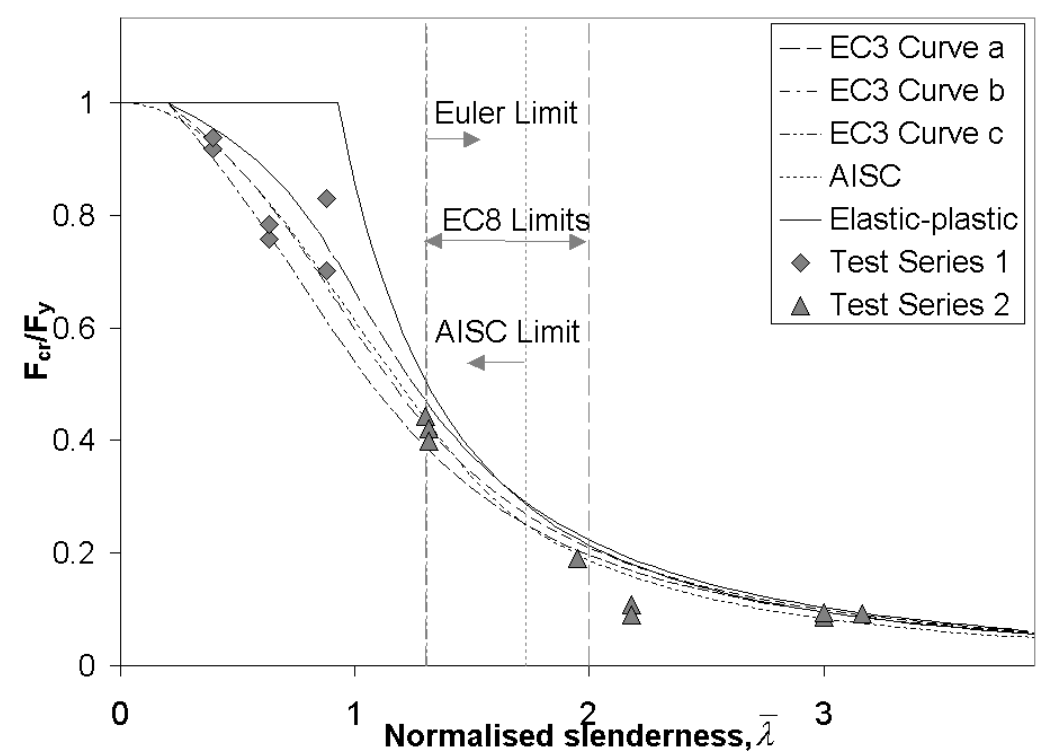

Figure 6. Normalised buckling loads of cyclic specimens.

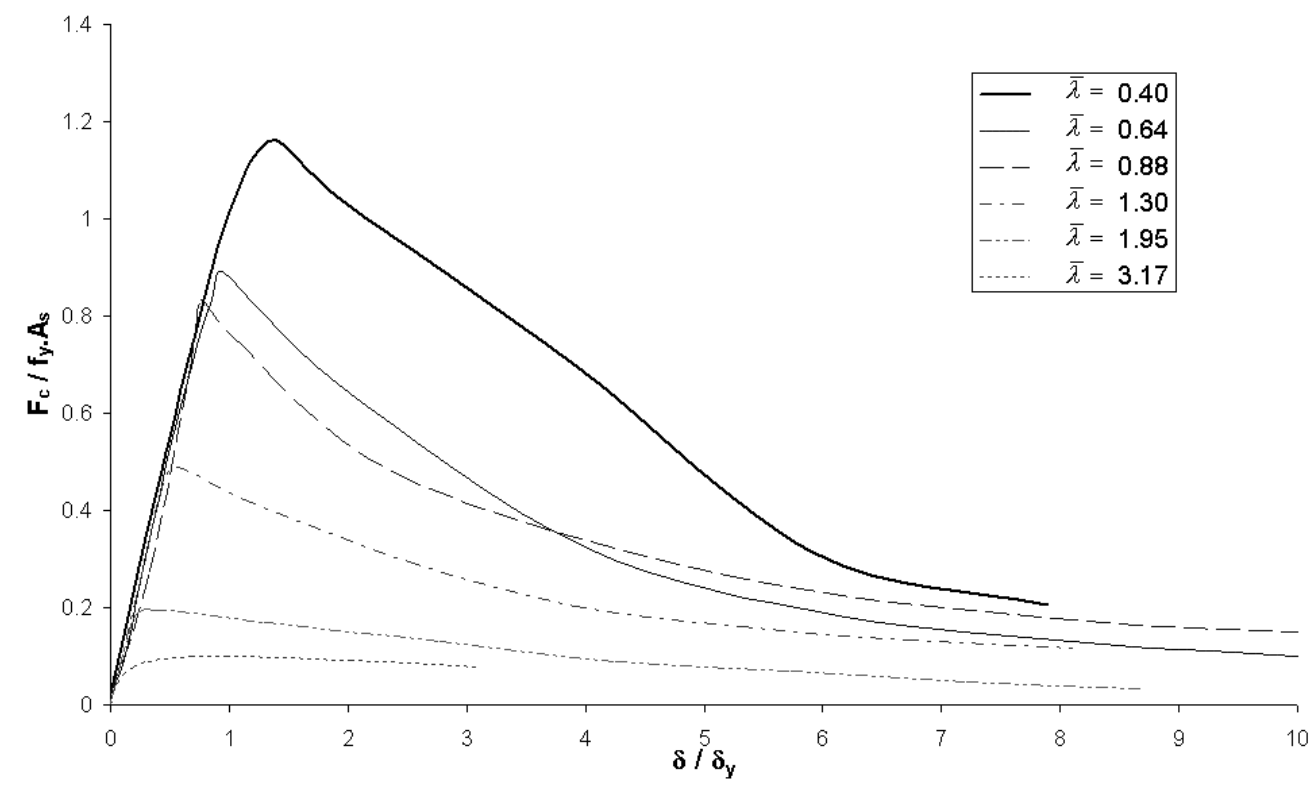

Figure 7. Compression envelope curves for cyclic specimens. 


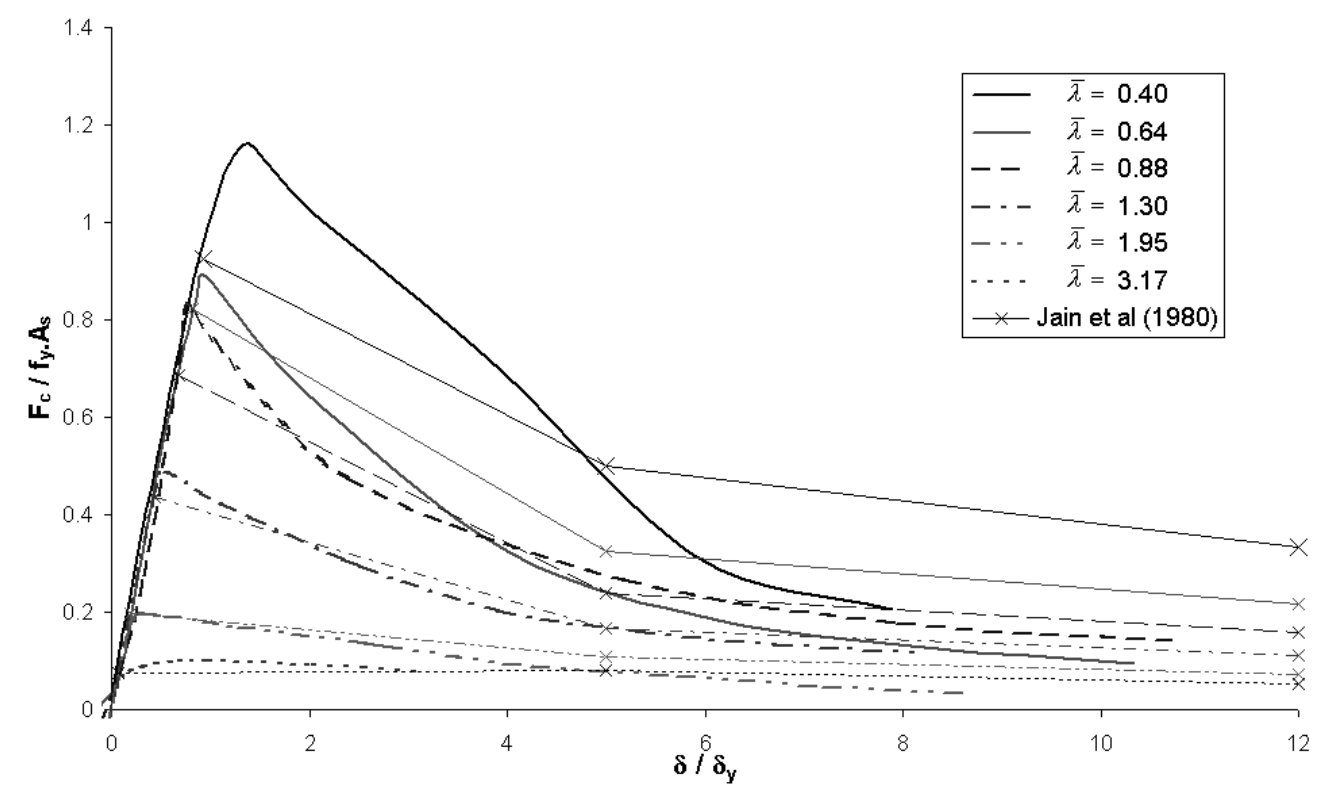

Figure 8. Comparison of post-buckling resistance with predictions by Jain et al (1980).

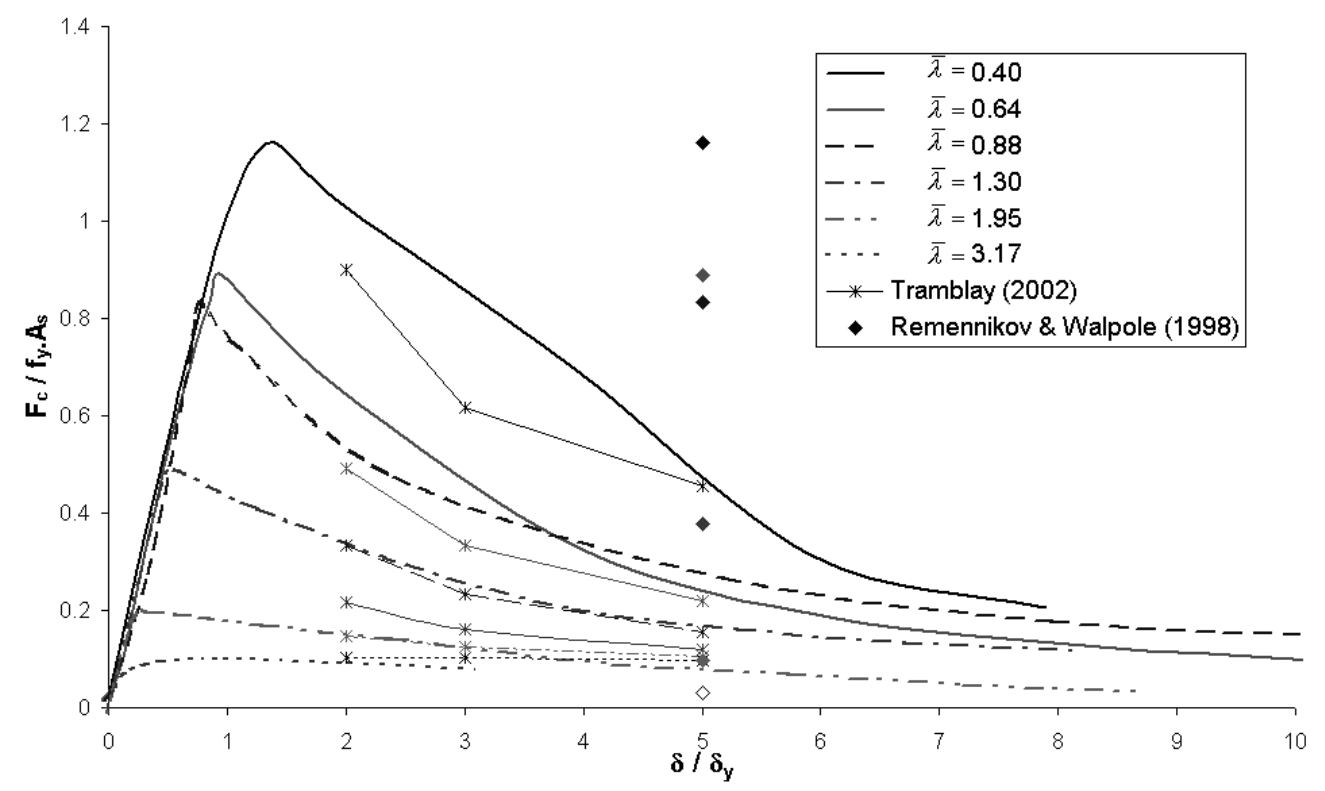

Figure 9. Comparison of post-buckling resistance with predictions by Tremblay (2002) and Remennikov \& Walpole (1998). 


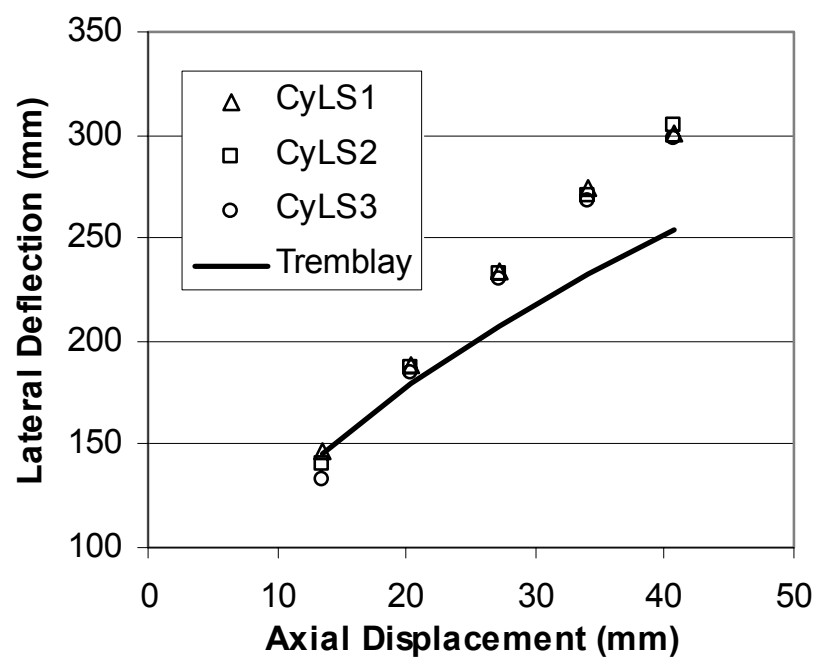

(a) 40x40x2.5 SHS Specimens

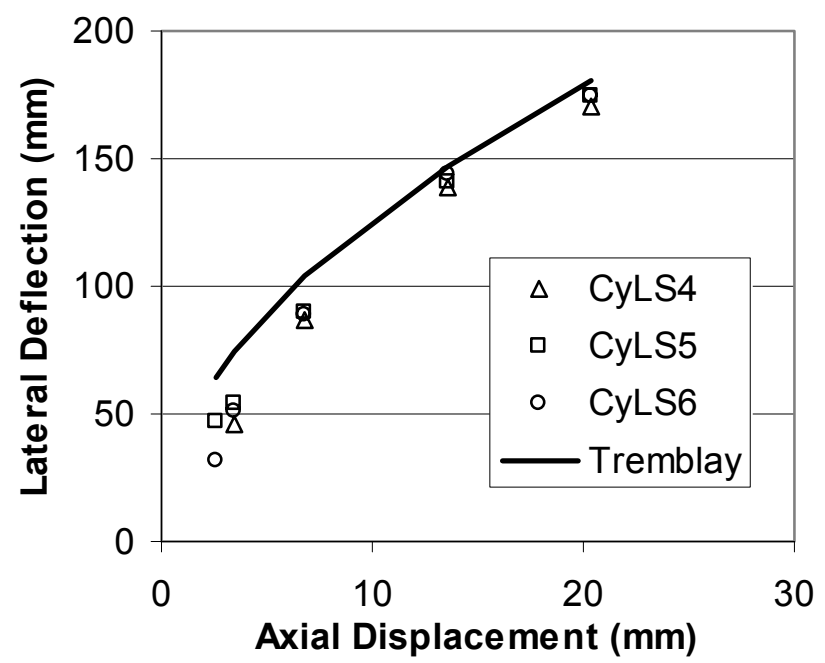

(b) $20 \times 20 \times 2.0$ SHS Specimens

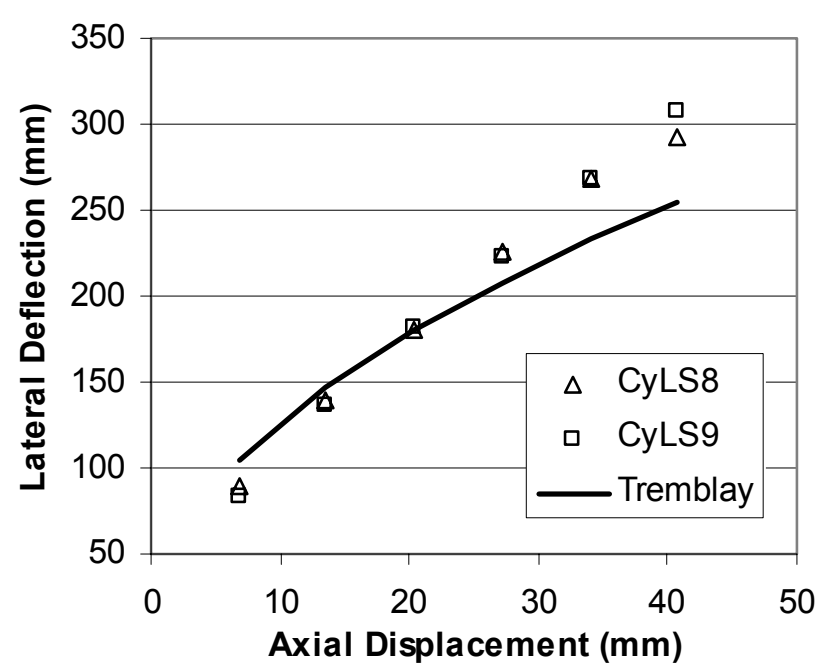

(c) $50 \times 25 \times 2.5$ RHS Specimens

Figure 10. Mid-length lateral deformations of cyclic test specimens. 
Table 1. Mean yield strengths of short specimens.

\begin{tabular}{|c|c|c|c|c|c|}
\hline Section size & $\begin{array}{l}\text { Coupon } \\
\text { test } \\
\text { results } \\
(\mathrm{MPa})\end{array}$ & $\begin{array}{l}\text { EC3 } \\
\text { model, } \\
\mathrm{f}_{\mathrm{ya}} \\
(\mathrm{MPa})\end{array}$ & $\begin{array}{l}\text { AISI } \\
\text { model, } \\
\mathrm{F}_{\mathrm{ya}} \\
(\mathrm{MPa})\end{array}$ & $\begin{array}{l}\text { Tensile } \\
\text { test } \\
\text { results } \\
(\mathrm{MPa})\end{array}$ & $\begin{array}{l}\text { Tensile } \\
\text { test / } \\
\text { coupon } \\
\text { test }\end{array}$ \\
\hline $40 \times 40 \times 2.5 \mathrm{SHS}$ & 343.0 & 378.2 & 371.6 & 418.6 & 1.23 \\
\hline $20 \times 20 \times 2.0 \mathrm{SHS}$ & 299.6 & 314.5 & 329.4 & 303.7 & 1.01 \\
\hline $50 \times 25 \times 2.5$ RHS & 285.0 & 310.3 & 304.5 & 328.1 & 1.15 \\
\hline
\end{tabular}

Table 2. Cyclic test programme and results.

\begin{tabular}{|c|c|c|c|c|c|c|c|c|}
\hline Test ID & Section Size & $\overline{\bar{\lambda}}$ & $\mathrm{d} / \mathrm{t}$ & $\begin{array}{l}\mathrm{F}_{\mathrm{y}} \\
\mathrm{kN}\end{array}$ & $\begin{array}{l}\delta_{\mathrm{y}} \\
\mathrm{mm}\end{array}$ & $\begin{array}{l}\mathrm{F}_{\max } \\
\mathrm{kN}\end{array}$ & $\begin{array}{l}\delta_{\mathrm{u}} \\
\mathrm{mm}\end{array}$ & $\mu_{\Delta}$ \\
\hline \multicolumn{9}{|l|}{ Series1 } \\
\hline CyIS1 & $40 \times 40 \times 2.5$ & 0.4 & 13.1 & 100.4 & 2.4 & 112.9 & 20.7 & 8.7 \\
\hline CyIS2 & $40 \times 40 \times 2.5$ & 0.4 & 13.1 & 101.5 & 2.4 & 112.4 & 17.8 & 7.5 \\
\hline CyIS3 & $20 \times 20 \times 2.0$ & 0.9 & 6.7 & 26.0 & 1.2 & 45.4 & 35.3 & 29.7 \\
\hline CyIS4 & $20 \times 20 \times 2.0$ & 0.9 & 6.7 & 29.8 & 1.1 & 46.0 & 22.6 & 20.9 \\
\hline CyIS5 & $50 \times 25 \times 2.5$ & 0.6 & 17.1 & 78.1 & 1.6 & 111.5 & 23.0 & 14.3 \\
\hline CyIS6 & $50 \times 25 \times 2.5$ & 0.6 & 17.1 & 83.1 & 1.8 & 111.5 & 21.8 & 12.2 \\
\hline \multicolumn{9}{|l|}{ Series2 } \\
\hline CyLS1 & $40 \times 40 \times 2.5$ & 1.3 & 12.9 & 123.1 & 4.3 & 143.9 & - & $9.5^{*}$ \\
\hline CyLS2 & $40 \times 40 \times 2.5$ & 1.3 & 12.9 & 124.1 & 4.4 & 143.8 & - & $9.2 *$ \\
\hline CyLS3 & $40 \times 40 \times 2.5$ & 1.3 & 12.9 & 126.5 & 5.7 & 142.5 & - & $7.2 *$ \\
\hline CyLS4 & $20 \times 20 \times 2.0$ & 3.2 & 6.5 & 63.1 & 7.0 & 70.2 & 16.0 & 2.3 \\
\hline CyLS5 & $20 \times 20 \times 2.0$ & 3.0 & 6.0 & 64.4 & 7.9 & 69.3 & 15.2 & 2.0 \\
\hline CyLS6 & $20 \times 20 \times 2.0$ & 3.0 & 6.0 & 63.6 & 6.0 & 72.3 & 16.7 & 2.8 \\
\hline CyLS7 & $50 \times 25 \times 2.5$ & 1.9 & 17.3 & 99.4 & 4.6 & 117.7 & - & $8.8^{*}$ \\
\hline CyLS8 & $50 \times 25 \times 2.5$ & 2.2 & 16.9 & 162.6 & 7.3 & 187.7 & - & $5.6^{*}$ \\
\hline CyLS9 & $50 \times 25 \times 2.5$ & 2.2 & 16.9 & 165.4 & 7.0 & 190.1 & - & $5.8^{*}$ \\
\hline
\end{tabular}

* Maximum displacement ductility demand. 
Table 3. Initial buckling loads and dissipated energy.

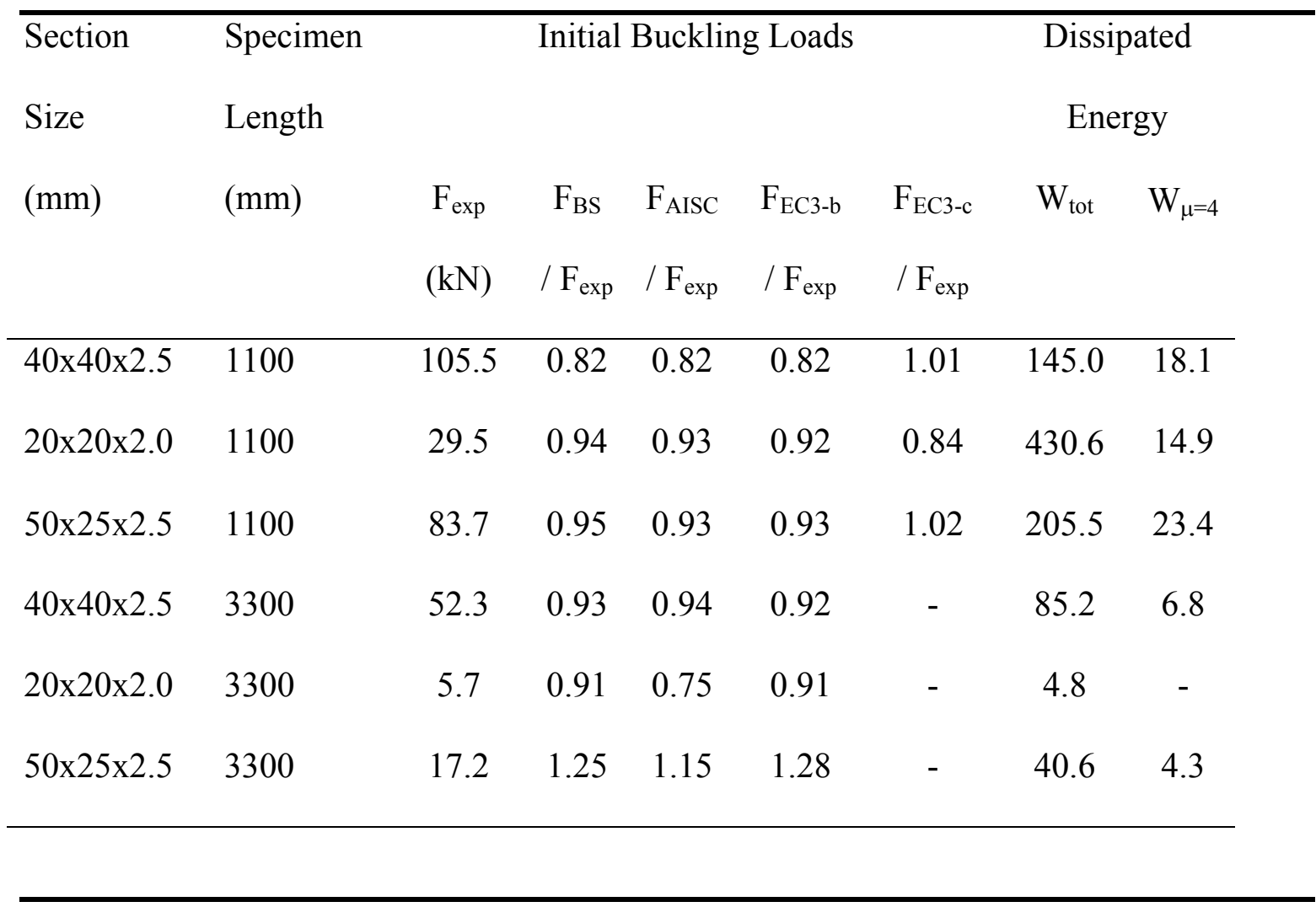

